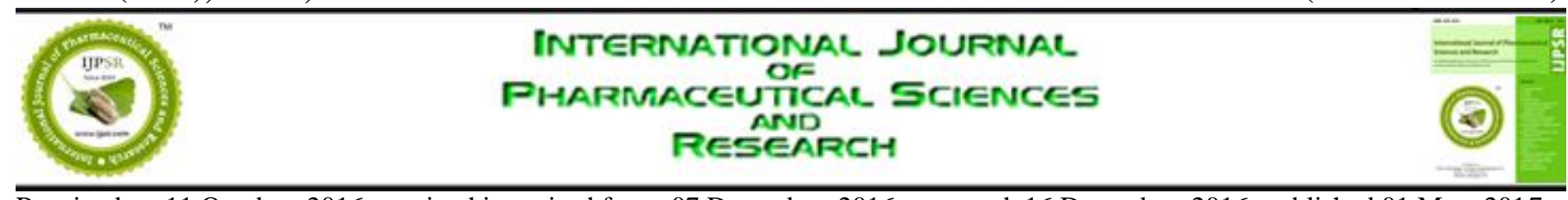

Received on 11 October, 2016; received in revised form, 07 December, 2016; accepted, 16 December, 2016; published 01 May, 2017

\title{
CHRONIC KIDNEY DISEASE AND COGNITIVE STATUS
}

\author{
P. C. Viji ${ }^{* 1}$, K. Sreejith ${ }^{1}$ and M. Sreelatha ${ }^{2}$
}

Department of Pharmacy Practice ${ }^{1}$, College of Pharmaceutical Sciences, Department of Nephrology ${ }^{2}$, Government Medical College, Calicut, Kerala, India.

Keywords:

Chronic kidney disease, Cognitive impairment, Montreal Cognitive Assessment Questionnaire

\section{Correspondence to Author:}

P. C. Viji

M. Pharm Student

Department of Pharmacy Practice College of Pharmaceutical Sciences Government Medical College Calicut, Kerala, India.

E-mail: vijichandran2310@gmail.com

\begin{abstract}
Background: The relation between Chronic Kidney Disease (CKD) and cognitive impairment is an important public health issue because the prevalence of CKD is increased worldwide. In recent years, chronic kidney disease has been proposed as an independent risk factor for cognitive decline but the available data are conflicting. In the present study, we examined the relations of CKD and lower renal filtration function with a broad range of cognitive functions in a dementia-free community-based population. Methods: A cross-sectional, observational, questionnaire based study was conducted at Nephrology department of Govt. Medical College, Calicut. Montreal Cognitive Assessment Questionnaire was used to assess cognitive status. Patient's divided into 5 groups depending on stage of chronic kidney disease. Estimated glomerular filtration rate was calculated using modification of diet in renal disease equation. Results: 210 patients were enrolled in the study. 53.8\% have mild cognitive impairment and $46.2 \%$ have normal cognitive status. Education with cognitive status was found to be statistically significant $(\mathrm{P}=0.000)$. Conclusion: Decreased kidney function associated with greater cognitive decline, even in those with mild CKD. Further studies are needed to determine the reasons for cognitive impairment in subjects with CKD.
\end{abstract}

INTRODUCTION: Chronic kidney disease (CKD) is a growing public health problem with evidence pointing to an increasing incidence and prevalence worldwide ${ }^{1}$. The prevalence of chronic kidney disease (CKD) increases with aging ${ }^{2}$. Cognition is the mental process of acquiring knowledge by the use of reasoning or perception and underlies all daily activities, from the most basic to the most complex. Cognitive dysfunction includes reduced mental alertness, intellectual impairment, decreased attention and concentration, memory deficits and diminished perceptual-motor coordination.

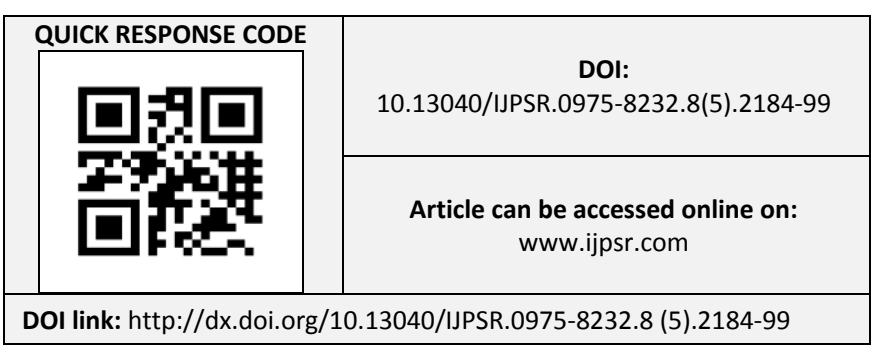

Cognitive impairment is associated with an increased risk of death, which is mostly due to cerebro-vascular disease and prevalence of traditional and non-traditional vascular risk factors in chronic kidney disease (CKD). It is important to identify those patients with cognitive impairment to reduce the considerable morbidity associated with this condition ${ }^{3}$.

The Montreal Cognitive Assessment (MoCA) is a screening test for cognitive impairment that covers major cognitive domains including episodic memory, language, attention, orientation, visuospatial ability and executive functions, while remaining brief and easy to administer. It is generally considered superior to the wellestablished Mini-Mental State Examination (MMSE) screening test, since the MoCA not only assesses executive functioning, which may be particularly important in the CKD population, but also presents a higher sensitivity for mild cognitive impairment ${ }^{4}$. 
Previous studies results concluded that CKD is associated with cognitive impairment. Several studies use different tools for assessing cognitive status. Because of the lack of data and conflicting results here evaluated the cognitive status among CKD patients (stages 3-5) with a specific and sensitive tool MoCA.

\section{MATERIALS \& METHODS:}

Study site: The Study was conducted in the Nephrology Department of Govt. Medical College, Calicut which is a Tertiary Care Teaching Hospital with Multi Specialty Departments.

Study design: The studies were observational and cross- sectional study.

Study period: This study was conducted over a period of six months.

Study approval: This study was approved by the ethical committee constituted by Govt. Medical College, Calicut.

\section{Study Materials:}

\section{Materials and Source of data:}

- Prescription of outpatients

- Treatment chart

- Laboratory reports

- By communication with physician, pharmacist, caregivers and patients

- Any other relevant sources

Patient consent form: An informed consent form was prepared in both English and Malayalam version for the convenience of patient.

Patient data collection form- It contains the sociodemographic details of the patients like Age, Sex, Education, Occupation, Smoking, Alcoholic, history details of HTN,DM,CKD, medication chart, laboratory reports etc.

\section{Questionnaires:}

Montreal cognitive assessment questionnaire: Cognitive status was checked by interviewing the patient with Montreal cognitive assessment questionnaire. It assesses different cognitive domains: attention and concentration, executive functions, memory, language, visuoconstructional skills, conceptual thinking, calculations and orientation. Time to administer the MoCA is approximately 10 minutes. The total possible score is 30 points. Add one point for an individual who has 12 years or fewer of formal education, for a possible maximum of 30 points. Score of 26 or above is considered as normal ${ }^{5}$.

Study procedure: Cross-sectional observational study was conducted at Nephrology department of Govt. Medical College, Calicut. This study was conducted over a period of 6 months from February 2016 to July 2016. Patients visiting Outpatients of nephrology department and who satisfy the inclusion criteria were enrolled in to the study. Ethical approval obtained from Institutional Ethics Committee of Govt. Medical College, Calicut, Kerala, India. Patient data collection form was prepared and the information was collected from the patient by interviewing the patient and also from the case records. Montreal Cognitive Assessment Questionnaire was used to assess the cognitive status. Informed consents were obtained from all participants enrolled in the study and questionnaire is used with permission.

\section{Inclusion criteria:}

- Patients having age between 19-79 years

- Patients with chronic kidney disease (stage 3-5)

- Minimum 3 months of disease duration

Exclusion criteria: Patients with

- Psychiatric disorders

- Neurological disorders

- Pregnant and lactating patients

- Blind patients

- Severe diabetic complication

- Patients below 18 years and above 80 years

- Renal transplant patients

- Patients with acute kidney disease

MDRD (modification of diet in renal disease) glomerular filtration rate equation: MDRD equation is more accurate as an estimator of kidney function. The working group of the National Kidney Foundation's (NKF) Kidney Dialysis Outcomes and Quality Initiative (K/DOQI) has developed a CKD classification system based on the presence of structural kidney damage and/or 
functional changes in glomerular filtration rate (GFR) present for a period of 3 months or more. CKD is categorized by the level of kidney function (as defined by GFR) into stages 1 through 5, with each increasing number indicating a more advanced stage of the disease.

Stage 1 includes GFR $\geq 90 \mathrm{~mL} / \mathrm{min}$, Stage 2 includes GFR 60-89 mL/min, Stage 3a includes GFR 45-59 mL/min, Stage 3b includes GFR 30-44 $\mathrm{mL} / \mathrm{min}$, Stage 4 includes GFR 15- $29 \mathrm{~mL} / \mathrm{min}$ and Stage 5 includes GFR $<15 \mathrm{~mL} / \mathrm{min}^{3}$.

$\mathrm{eGFR}\left(\mathrm{mL} / \mathrm{min} / 1.73 \mathrm{~m}^{2}\right)=186 \mathrm{X}[\mathrm{S} \mathrm{cr}(\text { umolL) }) 88.4]^{-1.154} \mathrm{XAge} \mathrm{e}^{-0.203}$ (for males)

eGFR $\left(\mathrm{mL} / \mathrm{min} / 1.73 \mathrm{~m}^{2}\right)=186 \mathrm{X}\left[\mathrm{S} \mathrm{cr}(\text { moliL) } 88.4]^{-1.154} \mathrm{XAge} \mathrm{e}^{-0.203} \mathrm{XO} 0.742\right.$ (for female)

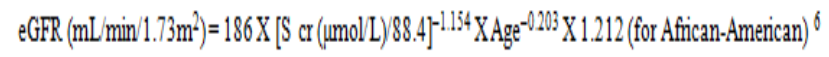

Statistical analysis: PASW Statistics version 18, 2009 software was used for statistical analysis. Data collected were analyzed using descriptive (Frequency and Percentage) statistics. The association of individual variables with cognitive status was determined by using Pearson chi-square method. $\mathrm{P}$ value of less than 0.05 was considered as significant.

RESULTS AND DISCUSSION: The data collected through interviews and case report reviews, were documented, tabulated and statistically analyzed and described with help of tables and graphs. Total 210 patients were enrolled in this study.

TABLE 1: BASELINE CHARACTERISTICS OF THE POPULATION

\begin{tabular}{|c|c|c|}
\hline Features & Number of patients & Percentage \\
\hline \multicolumn{3}{|c|}{ Gender } \\
\hline Male & 140 & 66.7 \\
\hline Female & 70 & 33.3 \\
\hline \multicolumn{3}{|c|}{ Age range (in years) } \\
\hline $31-40$ & 25 & 11.9 \\
\hline $41-50$ & 52 & 24.8 \\
\hline $51-60$ & 81 & 38.6 \\
\hline $61-70$ & 49 & 23.3 \\
\hline $71-80$ & 3 & 1.4 \\
\hline \multicolumn{3}{|c|}{ Educational Qualification } \\
\hline Lower Primary (1-4) & 40 & 19 \\
\hline Upper Primary (5-7) & 61 & 29 \\
\hline High School (8-10) & 87 & 41.5 \\
\hline $\begin{array}{l}\text { Pre-degree/Degree } \\
\qquad(>10)\end{array}$ & 22 & 10.5 \\
\hline \multicolumn{3}{|c|}{ Stage } \\
\hline $3 a$ & 31 & 14.8 \\
\hline
\end{tabular}

\begin{tabular}{ccc}
\hline $3 \mathrm{~b}$ & 48 & 22.9 \\
4 & 45 & 21.3 \\
5ND & 59 & 28.1 \\
5D & 27 & 12.9 \\
\multicolumn{2}{c}{ Medical history of co-morbidities } & \\
Nil & 25 & 11.9 \\
DM & 31 & 14.8 \\
HTN & 57 & 27.1 \\
DM+HTN & 49 & 23.2 \\
Others & 23 & 11 \\
DM + HTN + Others & 25 & 11.9 \\
\hline
\end{tabular}

DM: Diabetes Mellitus, HTN: Hypertension, ND: Non dialysis, D: Dialysis

Out of 210 patients, $140(66.7 \%)$ were males and $70(33.3 \%)$ ) were females (Table 1). This result was concordant with the nationwide survey of ESRD by the Japanese Society for Dialysis Therapy, revealed a higher incidence and prevalence in men than in women ${ }^{7}$. Manju et al study results also similar to the results, i.e. men are more prone to develop chronic kidney disease (CKD) and progress to endstage renal disease than are women ${ }^{8}$. The majority of CKD patients were in the age group 51-60 years. The minimum and maximum age included in the study was 31 and 76 years respectively (Table 1). This finding is consistent with Odagiri $\mathrm{G}$ et al study. The prevalence of CKD was high in elderly population and patients showed a higher prevalence of cognitive impairment in older groups (50 years and older) ${ }^{9}$.

$87(41.5 \%)$ patients in this study have high school educational level followed by 61 (29\%) having upper primary educational level, 40 (19\%) having lower primary educational level and only 22 $(10.5 \%)$ having pre-degree or degree educational level (Table 1). $59(28.1 \%)$ were in stage 5 (nondialysis). Remaining patient population were in $3 \mathrm{~b}(22.9 \%), 4(21.3 \%)$, 3a (14.8\%) and dialysis stage $(12.9 \%)$. Among the total sample of 210 patients, $25(11.9 \%)$ have CKD alone and 185 (88.1\%) have co-morbidities along with chronic kidney disease. 57 (27.1\%) have CKD along with hypertension, $31(14.8 \%)$ patients have CKD along with DM, 49 (23.2\%) have CKD+HTN+DM and $23(11 \%)$ have other diseases as co-morbidity (Table 1). A study by Salini et al also showed similar results that $34.18 \%$ patients were hypertensive, $22.78 \%$ were diabetics, $5.06 \%$ were dyslipidemic and $21.52 \%$ of patients had combination of hypertension and diabetes ${ }^{10}$. 
TABLE 2: PATIENT COGNITIVE STATUS

\begin{tabular}{cccc}
\hline Cognitive status & MoCA score & No of patients & Percentage \\
\hline Normal & $\geq 26$ & 97 & 46.2 \\
Mild cognitive impairment & $<26$ & 113 & 53.8 \\
Total & & 210 & 100 \\
\hline
\end{tabular}

MoCA: Montreal Cognitive Assessment

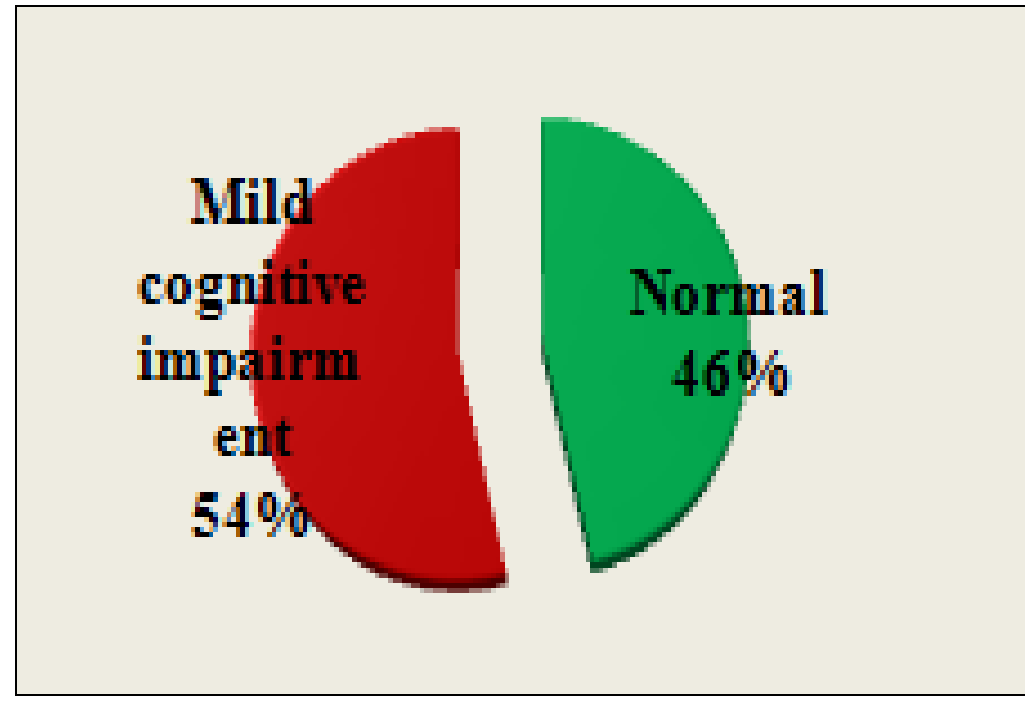

FIG 1: PATIENT COGNITIVE STATUS

$113(53.8 \%)$ have mild cognitive impairment and UE et al ${ }^{1}$, Sander D et al ${ }^{12}$ and Khatri M et al ${ }^{13}$ $97(46.2 \%)$ have normal cognitive status (Table 2 etc showed similar results with the study.

and Fig. 1). Studies by Madan $\mathrm{P}$ et al $^{11}$, Williams

Demographic details of patients with cognitive status:

TABLE 3: AGE WISE DISTRIBUTION OF PATIENTS WITH COGNITIVE STATUS

\begin{tabular}{|c|c|c|c|c|c|c|}
\hline \multirow[t]{2}{*}{ Age (yr) } & \multicolumn{2}{|c|}{ Normal } & \multicolumn{2}{|c|}{ Mild Cognitive Impairement } & \multirow[t]{2}{*}{ Total } & \multirow[t]{2}{*}{ P Value } \\
\hline & No of Patients & Percentage & No of Patients & Percentage & & \\
\hline $31-40$ & 14 & 56 & 11 & 44 & 25 & \\
\hline $41-50$ & 23 & 44.2 & 29 & 55.8 & 52 & \\
\hline $51-60$ & 37 & 45.7 & 44 & 54.3 & 81 & 0.456 \\
\hline $61-70$ & 23 & 46.9 & 26 & 53.1 & 49 & \\
\hline $71-80$ & 0 & 0 & 3 & 100 & 3 & \\
\hline Total & 97 & 46.2 & 113 & 53.8 & 210 & \\
\hline
\end{tabular}

41-70 age groups having similar mild cognitive impairment. Age group above 70 shows greater cognitive impairment compared to other age groups. Chi-square value of age group with cognitive status was not statistically significant (Table 3). In a study by Tiffin-Richards FE et al reveal negative association between the MoCA total score and age ${ }^{4}$.

TABLE 4: GENDER WISE DISTRIBUTION OF PATIENTS WITH COGNITIVE STATUS

\begin{tabular}{ccccccc}
\hline \multirow{2}{*}{ Gender } & \multicolumn{2}{c}{ Normal } & \multicolumn{2}{c}{ Mild Cognitive Impairement } & \multirow{2}{*}{ Total } & \multirow{2}{*}{ P Value } \\
\cline { 2 - 5 } & No of Patients & Percentage & No of Patients & Percentage & \\
\hline Male & 65 & 46.4 & 75 & 53.6 & 140 \\
Female & 32 & 45.7 & 38 & 54.3 & 70 \\
Total & 97 & 46.2 & 113 & 53.8 & 210 & 0.520 \\
\hline
\end{tabular}

Chi-square value of gender with cognitive status was not statistically significant. When comparing gender, females are more affected than males
(Table 4). A study by Odagiri $G$ et al results concordant with the study: gender is not statistically significant with cognitive status ${ }^{9}$. 
TABLE 5: EDUCATION OF PATIENTS WITH COGNITIVE STATUS

\begin{tabular}{ccccccc}
\hline Education Level & \multicolumn{2}{c}{ Normal } & \multicolumn{2}{c}{ Mild Cognitive Impairement } & Total & \multirow{2}{*}{ P Value } \\
\cline { 2 - 5 } & No of Patients & Percentage & No of Patients & Percentage & & \\
\hline Lower Primary & 5 & 12.5 & 35 & 87.5 & 40 & \\
Upper Primary & 22 & 36.1 & 39 & 63.9 & 61 & \\
High School & 52 & 59.8 & 35 & 40.2 & 87 & 0.000 \\
Pre-degree/Degree & 18 & 81.8 & 4 & 18.2 & 22 & \\
Total & 97 & 46.2 & 113 & 53.8 & 210 & \\
\hline
\end{tabular}

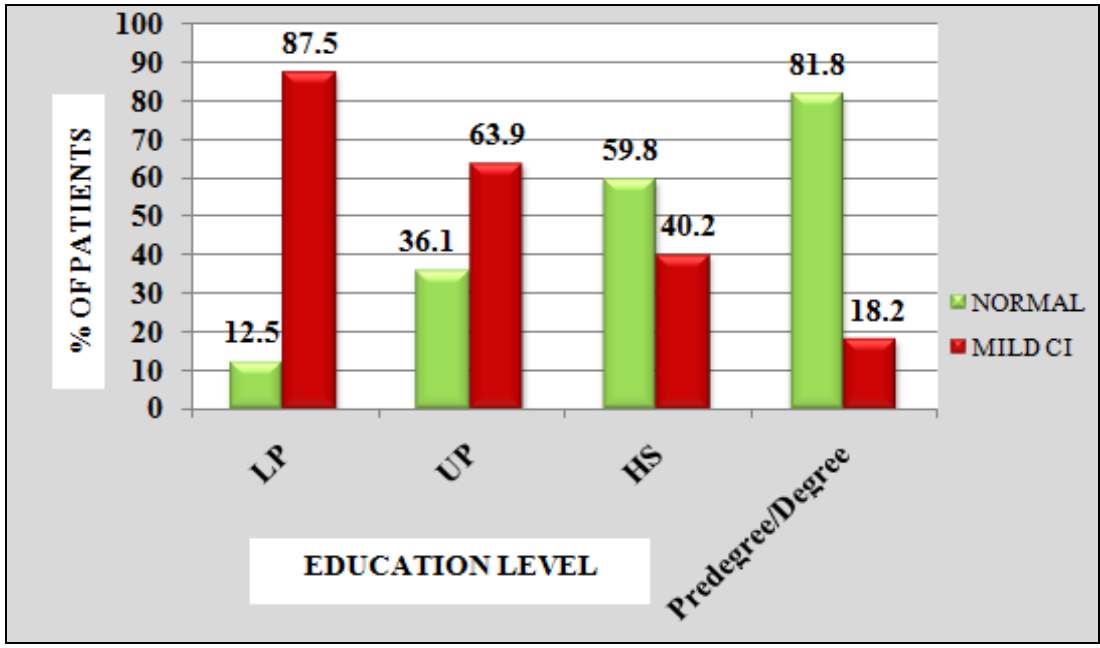

FIG 2: EDUCATION OF PATIENTS WITH COGNITIVE STATUS

Chi-square value of education level with cognitive status was statistically significant $(\mathrm{P}=0.000)$. Populations with lower education qualification have more cognitive impairment. Increased education qualification population shows improvement in cognitive status (Table 5 and Fig 2). A study by Odagiri $G$ et al results concordant with the study: level of education is significantly associated with cognitive status ${ }^{9}$.

TABLE 6: STAGE OF CKD PATIENTS WITH COGNITIVE STATUS

\begin{tabular}{ccccccc}
\hline Stage & \multicolumn{2}{c}{ Normal } & Mild Cognitive Impairement & Total & P Value \\
\cline { 2 - 5 } & No of Patients & Percentage & No of Patients & Percentage & & \\
\hline 3a & 13 & 41.9 & 18 & 58.1 & 31 & \\
3b & 24 & 50 & 24 & 50 & 48 & \\
4 & 20 & 44.4 & 25 & 55.6 & 45 & 0.896 \\
5ND & 29 & 49.2 & 30 & 50.8 & 59 & \\
5D & 11 & 40.7 & 16 & 59.3 & 27 & \\
Total & 97 & 46.2 & 113 & 53.8 & 210 & \\
\hline
\end{tabular}

Chi-square value of stage of CKD patient with cognitive status was not statistically significant. Cognitive impairment is not depended on stage of CKD. It is seen in all stages of CKD. CI is high in all stages (Table 6). A study by Kurella $M$ et al results is not concordant with study result: advanced stages of CKD were associated with an increased risk for cognitive impairment ${ }^{14}$.

TABLE 7: MEDICAL HISTORY OF COMORBIDITIES WITH COGNITIVE STATUS

\begin{tabular}{ccccccc}
\hline \multirow{2}{*}{ Comorbidity } & \multicolumn{2}{c}{ Normal } & Mild Cognitive Impairement & Total & \multirow{2}{*}{ P Value } \\
\cline { 2 - 5 } & No of Patients & Percentage & No of Patients & Percentage & & \\
\hline Nil & 9 & 36 & 16 & 64 & 25 & \\
DM & 19 & 61.3 & 12 & 38.7 & 31 & \\
HTN & 31 & 54.4 & 26 & 45.6 & 57 & \\
DM+HTN & 22 & 44.9 & 27 & 55.1 & 49 & 0.122 \\
Others & 8 & 34.8 & 15 & 62.5 & 23 & \\
DM+HTN+Others & 8 & 32 & 17 & 68 & 25 & \\
Total & 97 & 46.2 & 113 & 53.8 & 210 & \\
\hline
\end{tabular}


Chi-square value of co-morbidity with cognitive status was not statistically significant. The patient population with co-morbidities shows more cognitive impairment except in DM+CKD and $\mathrm{HTN}+\mathrm{CKD}$ groups. Majority of population in this study have mild cognitive impairment (Table 7).

CONCLUSION: The study concluded that CKD is one of the important diseases seen among the common people. Hypertension and Diabetes are the main causes of this disease. Females are more affected than males. Cognitive impairment is not depended on stage of CKD. It is seen in all stages of CKD.

ACKNOWLEDGMENTS: The authors are thankful to Dr. Ziad Nasreddine to give the copyright to use MoCA questionnaire and special thanks to Dr. Biju George for every suggestion and assistance.

\section{CONFLICT OF INTEREST: Nil}

\section{REFERENCES:}

1. Williams UE, Owolabi MO, Ogunniyi A, Ezunu EO: Prevalence and Pattern of Neurocognitive Impairment in Nigerians with Stages 3 to 5 Chronic Kidney Disease. ISRN Neurology 2013; 1-6.

2. Wang H, Fang C, Cai L, Dong B, Deng J: Chronic kidney disease and cognitive impairment among the very old in China. Aging Clinical and Experimental Research 2015 Aug; Springer.

3. Nasser MET, Shawki S, Shahawy YE, Sany D: Assessment of Cognitive Dysfunction in Kidney Disease.
Saudi Journal of Kidney Diseases and Transplantation 2012; 23(6):1208-1214.

4. Tiffin-Richards FE, Costa AS, Holschbach B, Frank RD, Vassiliadou A, Kruger T, et al: The Montreal Cognitive Assessment (MoCA) - A Sensitive Screening Instrument for Detecting Cognitive Impairment in Chronic Hemodialysis Patients. Plos One 2014 Oct; 9(10): 1-9.

5. Nasreddine ZS: MoCA Version 2014. www.mocatest.org

6. Walker R, Whittlesea C: Clinical Pharmacy and Therapeutics. Churchill Livingstone Elsevier, $5^{\text {th }}$ edition 2012.

7. Iseki K: Gender Differences in Chronic Kidney Disease. Kidney International 2008 Aug; 74(4): 415-417.

8. Manju CS, Anish B, Sreelatha M: Medication Adherence Associated with Polypharmacy in Chronic Kidney Disease Patients. International Journal of Pharmaceutical Sciences and Research 2016; 7(7): 3107-3111.

9. Odagiri G, Sugawara N, Kikuchi A, Takahashi I, Umeda $\mathrm{T}$, Saitoh $\mathrm{H}$, et al: Cognitive function among hemodialysis patients in Japan. Annals of General Psychiatry 2011; 10(20): 1-5.

10. Salini AB, Sajeeth CI: Prevalence, Risk Factors, Adherence and Non Adherence in Patient with Chronic Kidney Disease: A Prospective Study. International Journal of Research in Pharmacy and Chemistry 2013; 3(2): 404-410

11. Madan P, Kalra OP, Agarwal, Tandon OP: Cognitive Impairment in Chronic Kidney Disease. Nephrology Dialysis Transplantation 2007; 22: 440-444.

12. Etgen T, Chonchol M, Forstl H, and Sander D: Chronic Kidney Disease and Cognitive Impairment: A Systematic Review and Meta-Analysis. American Journal of Nephrology 2012 May; 35: 474-482.

13. Khatri M, Nickolas T, Moon YP, Paik MC, Rundek T, Elkind MSV: CKD Associates with Cognitive Decline. Journal of the American Society of Nephrology 2009; 20: 2427-2432.

14. Kurella M, Chertow GM, Fried LF, Cummings SR, Harris $\mathrm{T}$, Simonsick E, et al: Chronic Kidney Disease and Cognitive Impairment in the Elderly: The Health, Aging, and Body Composition Study. Journal of the American Society of Nephrology 2015; 16: 2127-2133.

How to cite this article:

Viji PC, Sreejith K and Sreelatha M: Chronic kidney disease and cognitive status. Int J Pharm Sci Res 2017; 8(5): 2184-99.doi: 10.13040/IJPSR.0975-8232.8(5).2184-99.

All @ 2013 are reserved by International Journal of Pharmaceutical Sciences and Research. This Journal licensed under a Creative Commons Attribution-NonCommercial-ShareAlike 3.0 Unported License.

This article can be downloaded to ANDROID OS based mobile. Scan QR Code using Code/Bar Scanner from your mobile. (Scanners are available on Google Playstore) 